\title{
Difference between left atrium function and size in athletes and healthy population
}

\section{DKrešimir Šutalo ${ }^{1,2 *}$, \\ (D)Ana Šutalo', (i) Renato Filjar 3,4}

'General Hospital “Dr. T. Bardek",Koprivnica, Croatia

2Polyclinic "Dr.

Došen“,Bjelovar, Croatia

${ }^{3}$ University of Rijeka, Faculty of Engineering, Rijeka,

Croatia

${ }^{4}$ Krapina University of Applied Sciences, Krapina, Croatia

\section{RECEIVED:}

March 28, 2021

ACCEPTED:

April 2, 2021

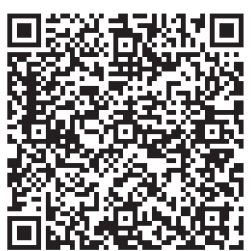

$\square$ Cardiologia Croatica 2021:16(5-6):198.
KEYWORDS: athletes, left atrium size, left atrium strain, 2D speckle tracking

CITATION: Cardiol Croat. 2021;16(5-6):198. | https://doi.org/10.15836/ccar2021.198

*ADDRESS FOR CORRESPONDENCE: KrešimirŠutalo, General Hospital „Dr. T. Bardek“, Ž. Sellingera bb, HR-48000 Koprivnica, Croatia. / Phone: +385-98-1617063; Fax: +385-48-251139 / E-mail: kresimir.sutalo@kc.t-com.hr

ORCID: Krešimir Šutalo, https://orcid.org/0000-0003-0719-0065 - Ana Šutalo, https://orcid.org/0000-0002-7644-6362 Renato Filjar, https://orcid.org/0000-0002-7040-9931

|I||||||||||||||||||||||||||||||||||||||||||||||||||||||||||||||||||||||||||||||||||||||||||||||||||||||||||||||||||||||||

Introduction: The function descriptors and size of the left atrium are commonly found in inversely proportional terms. Enlarged left atrium is the most common predictor of adverse cardiovascular event. ${ }^{1}$ Professional athletes are exposed to great physical exertion that leads to cardiac remodeling as a consequence of hemodynamic adaptation. Large meta-analyses confirmed that the linear dimensions and volume of the LA are significantly higher in athletes while the assessment of function is significantly more complex ${ }^{2}$

Patients and Methods: The aim of the study was to compare the difference between let atrium size and function in professional athletes and healthy people. The sample included 20 healthy individuals (17 female and 3 male), divided into two groups: athletes ( $N=12$ ) and control. The size of the left atrium was measured linearly using M mode and 2D, and by using biplane method from an apical position. All patients also underwent pulse and tissue Doppler and 2D speckle tracking analysis of left atrium. The following parameters were included: body surface area, left atrium diameter in M mode, left atrium endsystolic volume index, left ventricular mass index, mitral valve E wave velocity/mitral A wave velocity ratio, deceleration time, mitral valve $\mathrm{E}$ wave velocity/e' wave velocity lateral ratio, pulmonary vein systolic wave velocity/diastolic wave velocity ratio, pulmonary vein reversal A wave duration/ mitral valve A wave duration ratio, left atrium strain average reservoir, left atrium strain average conduit, left atrium strain average conduit contraction, and left ventricular global longitudinal strain. All exams were done on Philips Epiq 7G, and quantified off-line by Philips QLAB Autostrain.

Results: Statistically significant difference between two groups was identified for variables: mitral valve E wave velocity/mitral A wave velocity ratio, left atrium strain average reservoir, left atrium strain average conduit. For all three variables the values were higher in the athletes group.

Conclusion: Our study did not show difference in size of the left atrium between two groups. Significantly higher values of global deformation of the left atrium, represented by the average value of the reservoir function, the average conduit strain and the mitral valve E wave velocity/mitral A wave velocity ratio, were noticed in the athletes group. We infer the cause lies in the better compliance of LA, associated with increased left atrium passive emptying volumes ${ }^{3}$.

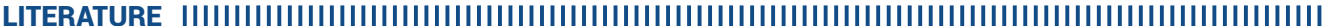

1. Tsang TS, Abhayaratna WP, Barnes ME, Miyasaka Y, Gersh BJ, Bailey KR, et al. Prediction of cardiovascular outcomes with left atrial size: is volume superior to area or diameter? J Am Coll Cardiol. 2006 Mar 7;47(5):1018-23. https://doi.org/10.1016/j.jacc.2005.08.077

2. Cuspidi C, Tadic M, Sala C, Gherbesi E, Grassi G, Mancia G. Left atrial function in elite athletes: A meta-analysis of two-dimensional speckle tracking echocardiographic studies. Clin Cardiol. 2019 May:42(5):579-587. https://doi.org/10.1002/clc.23180

3. Blume GG, Mcleod CJ, Barnes ME, Seward JB, Pellikka PA, Bastiansen PM, Tsang TS. Left atrial function: physiology, assessment, and clinical implications. Eur J Echocardiogr. 2011 Jun;12(6):421-30. https://doi.org/10.1093/ejechocard/jeq175 